Supporting Information

\title{
Stable and Efficient Near-Infrared Organic Light-Emitting Diodes Employing a Platinum(II) Porphyrin Complex
}

Linyu $\mathrm{Cao}^{1}$, Jingjun $\mathrm{Li}^{2}$, Zhi-Qiang Zhu ${ }^{1}$, Liang Huang ${ }^{1}$, and $\mathrm{Jian}^{\mathrm{Li}}{ }^{1 *}$

${ }^{1}$ Materials Science and Engineering, Arizona State University, Tempe, Arizona 85287, United States. ${ }^{2}$ Materials Science and Engineering, Cornell University, Ithaca, New York 14853, United States.*e-mail: jian.li.1@asu.edu.

Keywords: near-infrared emission, NIR OLEDs, platinum porphyrin complexes, stable OLEDs, efficient NIR OLEDs

\section{Synthesis of ZnTPTNP:}

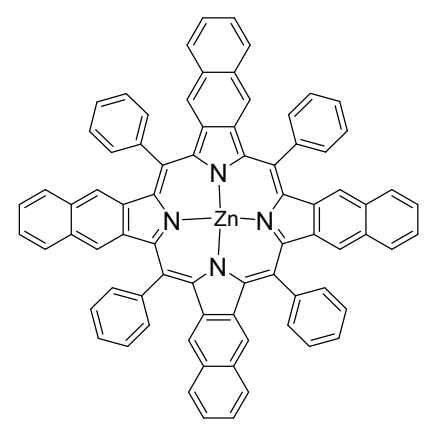

1H-benzo[f]isoindole-1,3(2H)-dione $(2.0 \mathrm{~g}, 10.14 \mathrm{mmol})$ and phenylacetic acid $(2.8 \mathrm{~g}, 20.28 \mathrm{mmol})$ were loaded into a round-bottom flask. The mixture was melted and stirred for 0.5 hour at $200{ }^{\circ} \mathrm{C}$ under a nitrogen atmosphere. $\mathrm{ZnO}(0.21 \mathrm{~g}, 2.54 \mathrm{mmol})$ was added to the melted mixture, and then heated at $310^{\circ} \mathrm{C}$ for 5 hours. After that, the reaction mixture was cooled down to room temperature, and purified by column chromatography on $\mathrm{Al}_{2} \mathrm{O}_{3}$ using DCM and THF (200:1-50:1) as eluent to afford the desired product ZnTPTNP as a dark-green solid (0.60 g, yeild: $22 \%) .{ }^{1} \mathrm{H}$ NMR $\left(400 \mathrm{MHz}, \mathrm{CDCl}_{3}, \delta\right): 8.31(\mathrm{~d}, J=6.5 \mathrm{~Hz}$, 8H), ), 8.07 (t, $J=7.3 \mathrm{~Hz}, 4 \mathrm{H}), 7.93$ (t, $J=7.5 \mathrm{~Hz}, 8 \mathrm{H}), 7.70-7.64(\mathrm{~m}, 12 \mathrm{H}), 7.45-7.40(\mathrm{~m}, 12 \mathrm{H})$. 


\section{Synthesis of $\mathrm{H}_{2}$ TPTNP:}

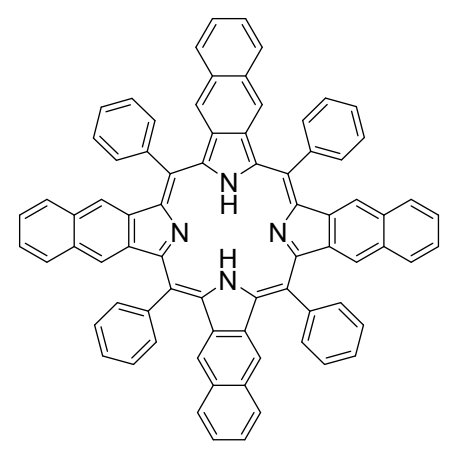

To a solution of ZnTPTNP $(0.15 \mathrm{~g}, 0.14 \mathrm{mmol})$ in $15 \mathrm{~mL}$ of dichloromethane (DCM) was added $15 \mathrm{~mL}$ of $6 \mathrm{M}$ hydrochloric acid aqueous solution. The mixture was stirred at room temperature for 20 minutes, and then was extracted with DCM for three times. The combined organic layer was concentrated and the residue was purfied by column chromatography on $\mathrm{Al}_{2} \mathrm{O}_{3}$ using DCM and hexane $(1: 10-1: 2)$ as eluent to afford the desired product $\mathrm{H}_{2}$ TPTNP as a dark-green solid (0.11 g, yield: $\left.80 \%\right) .{ }^{1} \mathrm{H}$ NMR (400 MHz, $\left.\mathrm{CDCl}_{3}, \delta\right): 8.45$ (d, $J=6.7 \mathrm{~Hz}, 8 \mathrm{H})$, ), 8.07 (t, $J=7.4 \mathrm{~Hz}, 4 \mathrm{H}), 7.96$ (t, $J=7.6 \mathrm{~Hz}, 8 \mathrm{H}), 7.76-7.62$ (br, 12H), 7.56-7.31 (br, $12 \mathrm{H})$.

\section{Synthesis of PtTPTNP:}

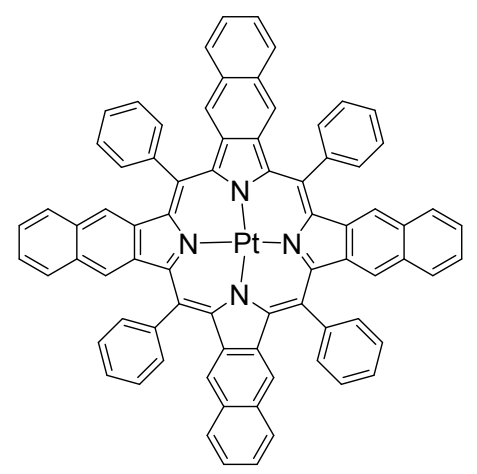

$\mathrm{PtCl}_{2}(0.026 \mathrm{~g}, 0.098 \mathrm{mmol})$ was dissolved in $1 \mathrm{~mL}$ of benzonitrile and was stirred for $20 \mathrm{~min}$ at $100{ }^{\circ} \mathrm{C}$ under a $\mathrm{N}_{2}$ atmosphere. $\mathrm{H}_{2}$ TPTNP $(0.050 \mathrm{~g}, 0.049 \mathrm{mmol})$ and $5 \mathrm{~mL}$ of anisole was added into the solution, and then the mixture was stirred overnight at $160^{\circ} \mathrm{C}$. The mixture was cooled down to room temperature, and then the solvent was removed under reduced pressure. The residue was purified through column 
chromatography on $\mathrm{Al}_{2} \mathrm{O}_{3}$ using DCM and hexane (1:10-1:1) as eluent to afford the desired product PtTPTNP as dark-green powder (0.054g, yield: 92\%). ${ }^{1} \mathrm{H}$ NMR (400 MHz, $\left.\mathrm{CDCl}_{3}, \delta\right): 8.36(\mathrm{~d}, J=7.7 \mathrm{~Hz}$, $8 \mathrm{H}), 8.08$ (t, $J=7.7 \mathrm{~Hz}, 4 \mathrm{H}), 7.97$ (t, $J=7.4 \mathrm{~Hz}, 8 \mathrm{H}), 7.73-7.58$ (br, 12H), 7.54-7.37 (br, 12H).

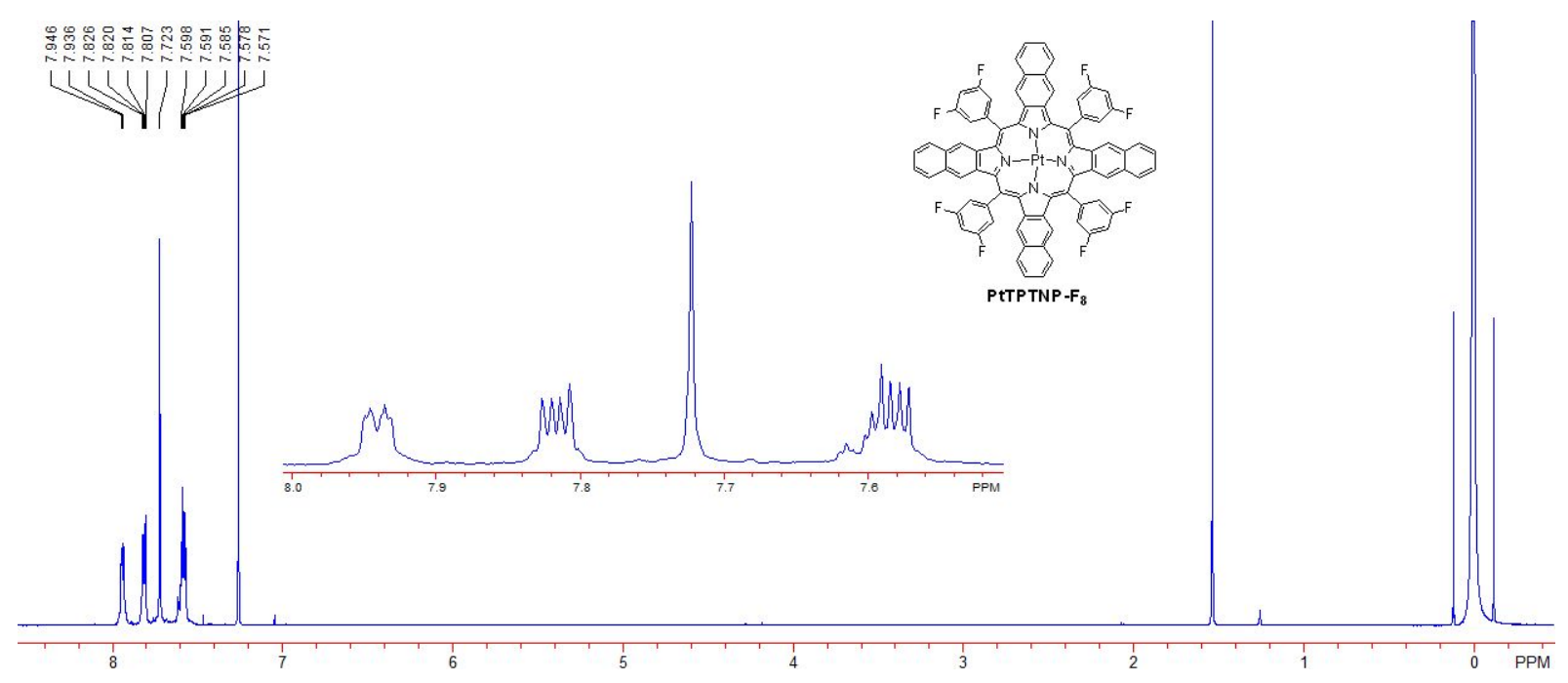

Figure S1. ${ }^{1} \mathrm{H}$ NMR of PtTPTNP-F.

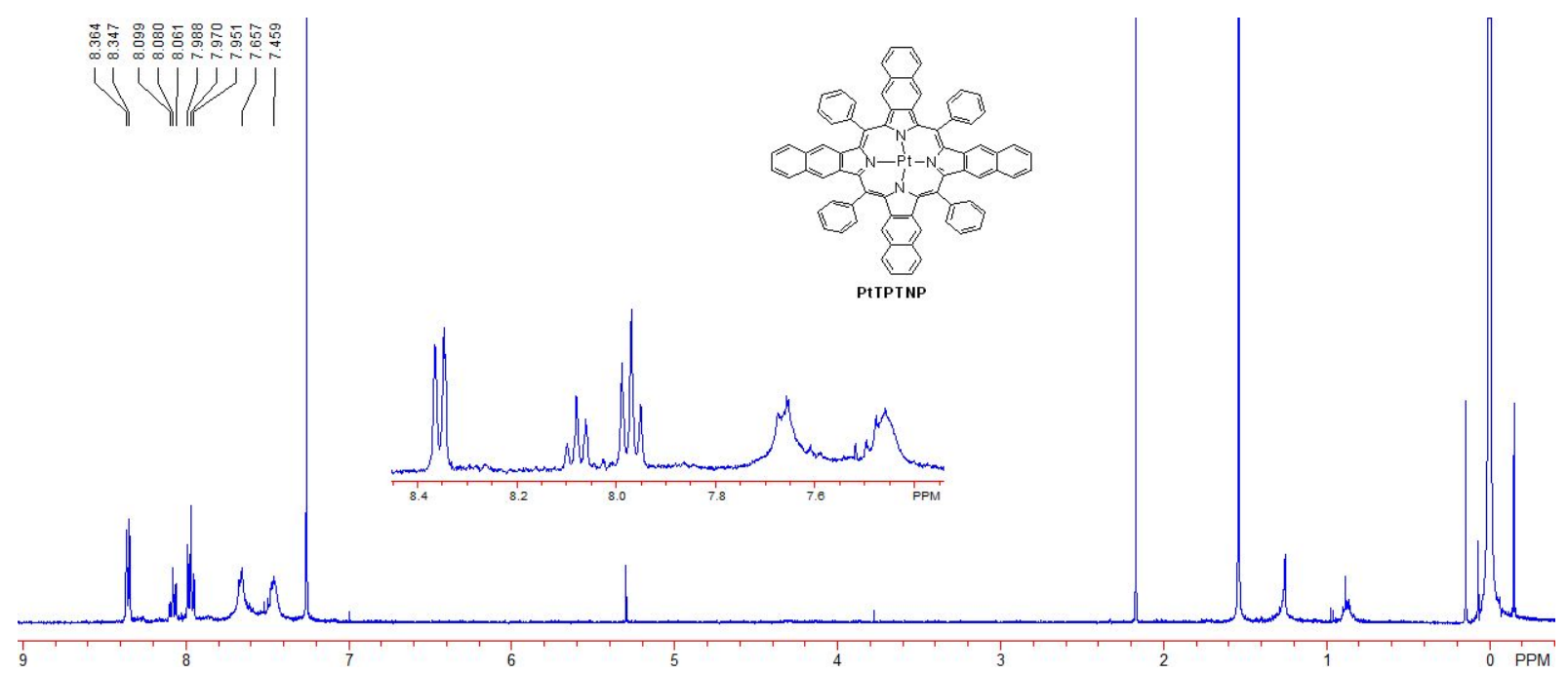

Figure S2. ${ }^{1} \mathrm{H}$ NMR of PtTPTNP. 


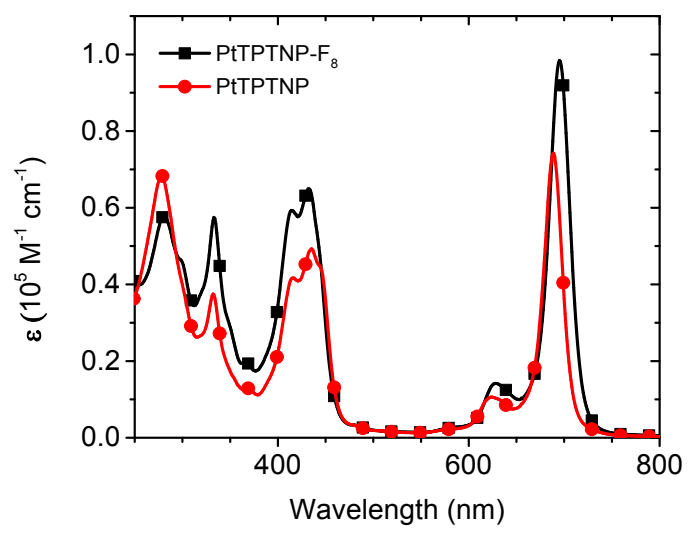

Figure S3. Room temperature absorption spectra of PtTPTNP-F 8 and PtTPTNP.

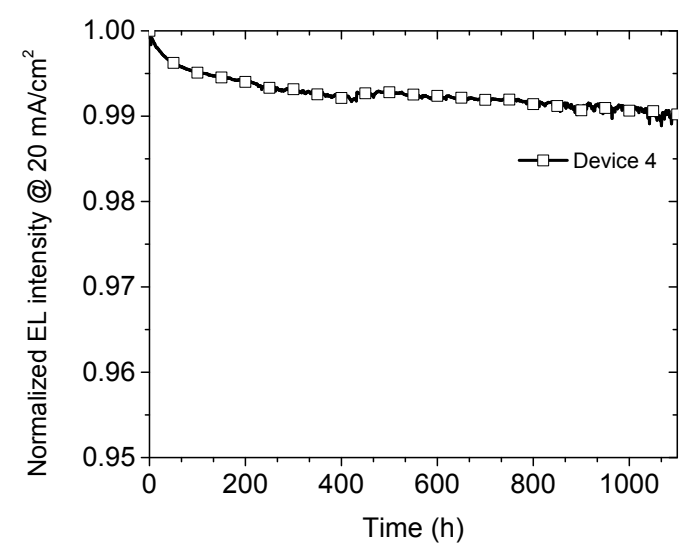

Figure S4. Relative EL intensity versus operational time at a constant current density of $20 \mathrm{~mA} \mathrm{~cm}^{-2}$ for device 4. 